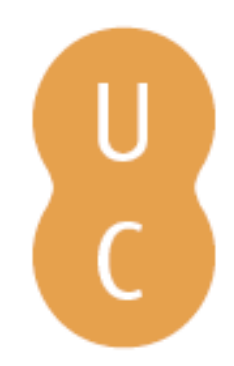

\title{
Rompalina
}

\section{Statistical evaluation of site-specific wildfire risk index calculation for Adriatic regions}
Autor(es):
Bugari, Marin; Stipaniev, Darko; Šeri, Ljiljana
Publicado por: Imprensa da Universidade de Coimbra
URL
persistente:
URI:http://hdl.handle.net/10316.2/34345
DOI:
DOI:http://dx.doi.org/10.14195/978-989-26-0884-6_138
Accessed : $\quad$ 26-Apr-2023 16:02:43

A navegação consulta e descarregamento dos títulos inseridos nas Bibliotecas Digitais UC Digitalis, UC Pombalina e UC Impactum, pressupõem a aceitação plena e sem reservas dos Termos e Condições de Uso destas Bibliotecas Digitais, disponíveis em https://digitalis.uc.pt/pt-pt/termos.

Conforme exposto nos referidos Termos e Condições de Uso, o descarregamento de títulos de acesso restrito requer uma licença válida de autorização devendo o utilizador aceder ao(s) documento(s) a partir de um endereço de IP da instituição detentora da supramencionada licença.

Ao utilizador é apenas permitido o descarregamento para uso pessoal, pelo que o emprego do(s) título(s) descarregado(s) para outro fim, designadamente comercial, carece de autorização do respetivo autor ou editor da obra.

Na medida em que todas as obras da UC Digitalis se encontram protegidas pelo Código do Direito de Autor e Direitos Conexos e demais legislação aplicável, toda a cópia, parcial ou total, deste documento, nos casos em que é legalmente admitida, deverá conter ou fazer-se acompanhar por este aviso.

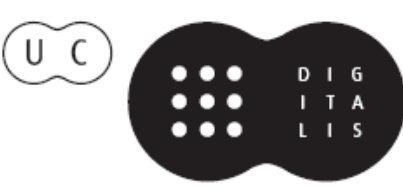




\section{ADVANCES IN}

Forest Fire

\section{RESEARCH}

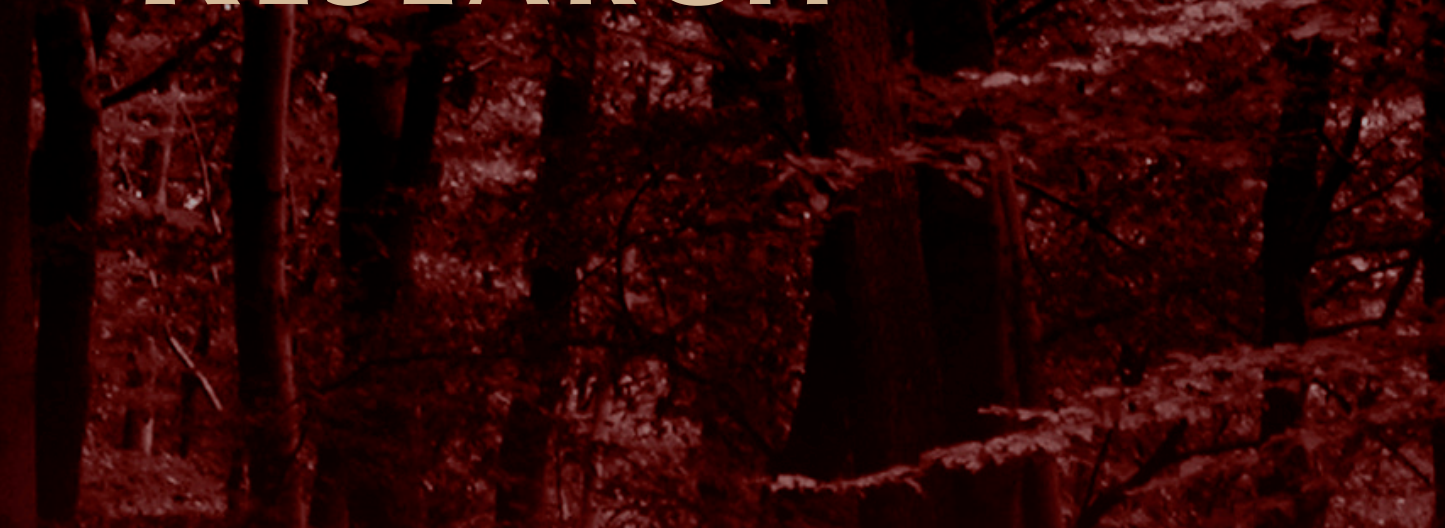

\section{DOMINGOS XAVIER VIEGAS}

\section{EDITOR}




\title{
Statistical evaluation of site-specific wildfire risk index calculation for Adriatic regions
}

\author{
Marin Bugarić, Darko Stipaničev, Ljiljana Šerić \\ University of Split Faculty of Electrical Engineering, Mechanical Engineering and Naval \\ Architecture, Department for Modelling and Intelligent Systems Ruđera Boškovića 32, 1000 Split, \\ Croatia. marin.bugaric@fesb.hr
}

\begin{abstract}
Wildfires are great threat to nature and humans. Predicting fire occurrence, early fire detection and intervention can significantly diminish hazardous consequences. Therefore, fire risk index is used to quantify probability of fire occurrence at certain time and place, in order to help fire managers to organize fire protection in a better way. In this paper we have performed statistical analysis of past fires detected by satellites in respect to various parameters. We have taken into account meteorological, topological and anthropological parameters and study their influence on fire occurrence. Based on this study we proposed an improved method for calculating a sitespecific fire risk index (SWRI), especially tuned for the Adriatic region.
\end{abstract}

Keywords: wildfires, wildfire risk index, Adriatic region, statistical evaluation

\section{Introduction}

Wildfires are important class of natural hazards especially in areas with mild and hot climate such as Mediterranean region. Fire management deals with predicting, preventing and detecting wildfires, as well as fire suppression after it ignites. For all these activities, fire risk index can be useful indicator. Fire risk index represents a numerical description probability of fire ignition and spread on a certain place and time. Wildfire risk index determination is of great importance for both wildfire prevention and protection. Even before the actual wildfire, identifying the fire danger is of great importance as it can be useful for planning firefighting activities. By using wildfire risk index, it is possible to achieve a more successful surveillance of the surrounding terrain by raising the level of alertness of automatic fire detection system or human observers on areas where current risk index is high. Beside that, wildfire risk index could help improve fire alertness for all the citizens who may be affected by wildfires.

Most countries exposed to wildfires have either developed or use one of the existing methods for wildfire risk index calculation. However, most of these indexes are not adequate for the use in the Adriatic region. Even more, not many existing wildfire risk indexes were site-specific developed with a focus on a micro-location, and therefore they have a rather low spatial resolution.

In this paper we propose a calculation method for Site-specific Wildfire Risk Index (SWRI) with quite satisfactory spatial resolution. The proposed wildfire risk index is not based solely on the meteorological parameters, like most existing wildfire risk indexes. It also takes into account other parameters for which we have, after carrying out a detailed statistical analysis, proven that they have a significant influence on the risk of wildfires in the Adriatic region, particularly on the central part of the Adriatic. More specifically, the proposed wildfire risk index is based on the following parameters: climatological and meteorological parameters, vegetation, terrain configuration and anthropogenic parameters. An example of the developed site-specific wildfire risk index for Split and Dalmatia County in Croatia, during a relatively high-risk index is shown in Figure 1. 


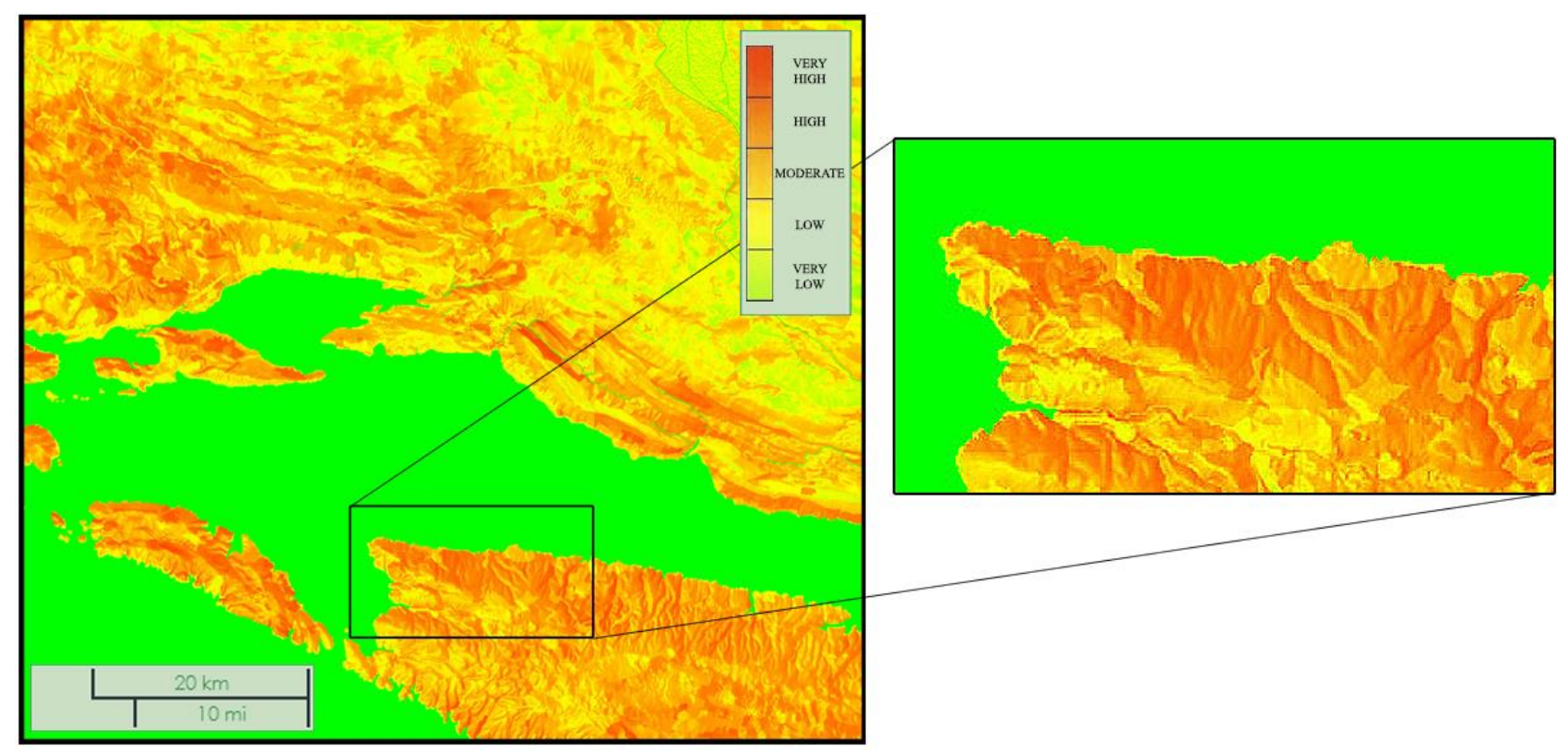

Figure 1. An example showing the proposed micro-location wildfire risk index

Our paper is organized as follows: In Section 2 we give a short overview of the existing wildfire risk indexes. In Section 3 we describe all the data required for a statistical evaluation of the proposed wildfire risk index in the Adriatic region. In Section 4 we studied different parameters in detail and calculated the correlation with wildfire frequency in the past for the Adriatic region. In Section 5 we define what we mean by a site-specific wildfire risk index. Finally, in Section 6 we carried out the evaluation of the proposed index.

\section{Related work}

In fire management, operatives usually use some kind of risk predication and assessment. Also, many counties adopted or developed a method for fire risk index calculation. Wildfire risk indexes are often classified into two categories: static and dynamic ((Gould, 2003, (Hernandez-Leal, 2008, (San-MiguelAyanz, 2002). Static indicators of wildfires change slowly over time; therefore they can be computed once before each fire season. In contrast, dynamic indicators of wildfires depend upon current conditions and must be calculated at least on a daily basis.

In the United States, National fire danger rating system (NFDRS, 1988) is used for ignition and spread risk assessment. Widely used fire risk index is Canadian Fire Weather Index (FWI), based on Canadian empirical fire model (FWI, 2009). FWI is calculated on the basis of weather conditions (temperature, humidity, wind, rain). Some authors also propose risks estimation based on Normalized Difference Vegetation Index (NDVI, 2014) obtained by remote sensing. In Europe, frequently used wildfire risk index is European Forest Fires Risk Forecasting System (EFFRFS) ((Gould, 2003, (San-MiguelAyanz, 2002), where the probability of fire occurrence and likely damage belong to static indicators, and meteorological fire risk and vegetation stress fire risk belong to dynamic indicators.

Geographic information system is used in wildfire risk models described in ((Erten, 2002, (Setiawan, 2004). In ((Zhijun, 2009) elevation, meteorological conditions and vegetation belong to main parameters for wildfire risk index. Other solutions were also proposed like (Silveira, 2008, Preisler, 2004, Vasilakos, 2007, (Netolicki, 2012, (Bugaric et al., 2009).

We used a slightly different approach. First we performed a detail statistical analysis of input parameters important for wildfire risk index calculation for Split and Dalmatia County. Based on this analysis a number of parameters were selected and in this first version of our model a linear correlation 
of selected parameters was considered. Genetic algorithms were used for calculation of coefficients in the model. The final evaluation has confirmed the reasonable assumptions of our model.

\section{Input data for the statistical analysis}

Meteorological data used for the impact assessment of different parameters on a site-specific wildfire risk index were collected for the time period from January $1^{\text {st }} 2012$. to January $1^{\text {st }} 2014$. Croatian Meteorological and Hydrological Service (DHMZ) calculates Canadian wildfire index (FWI) for several meteorological station across Adriatic coast several times a day. In collaboration with DHMZ, we have collected for Split-Dalmatia County their FWI as well as other meteorological data concerning wind, rain and humidity, with spatial resolution of $2 \mathrm{~km}$.

Vegetation parameters were based on Corine Land Cover (CLC) categorization. Unfortunately, fuel maps that classify vegetation in relation to the characteristics of combustibility were not developed for the Adriatic region. We proposed a simple conversion table to convert from CLC classification to a well-known Fire Behaviour Prediction System (FBPS) models introduced by ((Burgan, 1998, (Anderson, 1982, (Scott \& Burgan, 2005).

Terrain configuration data was based on NASA SRTM (Shuttle Radar Topography Mission) ((van Zyl, 2001). These data are currently distributed free of charge, and provide digital elevation model with 3-arc seconds resolution (approximately 90m) for the Adriatic region.

Anthropogenic parameters were extracted from OpenStreetMap ((OpenStreetMap, ) that is open data, licensed under the Open Data Commons Open Database License (ODbL). More specifically, we extracted information about roads, railroads, buildings and transmission lines.

The evaluation of the proposed site-specific wildfire risk index was performed using history of wildfires database. This database is based on MODIS ((NASA, ) data from Terra and Aqua satellites, which are capable of detecting wildfires with minimal area $1 \mathrm{~km} 2$. History of wildfires was collected for the period from January 1st 2001 to January 1st 2013 and consists of 1146 records of fire in SplitDalmatia County.

A site-specific wildfire risk index (SWRI) was completely implemented using GRASS GIS ((NASA, 2014) http://earthdata.nasa.gov/data/near-real-time-data/data/firms/active-fire-data, Active Fire Data $\mid$ EOSDIS - Earth Data Website, 06. June 2014.

(NDVI, 2014) http://earthobservatory.nasa.gov/Features/MeasuringVegetation/

(Neteler \& Mitasova, 2008) software and for visualization Mapserver (Mapserver, 2014) as well as Open Source Web GIS technology based on Openlayers (Openlayers, 2014) were used. First the impact assessment of input parameters on the site-specific wildfire risk index in the Adriatic region is given. Please note that all the values were normalized into interval [0-255] where 0 represents low, and 255 high wildfire risk index. For most of the parameters we have calculated Pearson correlation coefficient (Pearson, 1805), later used in model definition.

\section{Impact assessment of input parameters on wildfire risk index}

\subsection{Climatological and meteorological parameters}

While meteorological parameters refer to current weather parameters, climate refers to pattern of meteorological parameters over long periods of time. Climatological parameters can influence wildfire risk index in several ways. Climatological parameters determine the type of vegetation growing at certain territory. Drier climate usually means higher value of insolation and air temperature. Finally, strong winds can also have a great impact on the wildfire rate of spread, and thus on wildfire risk index. The proposed SWRI index is a dynamic index, where dynamics depends mostly on meteorological and climatological parameters. In our solution, wildfire risk index depends on: temperature, relative humidity, rainfall, wind speed, wind direction and cumulative FWI. 


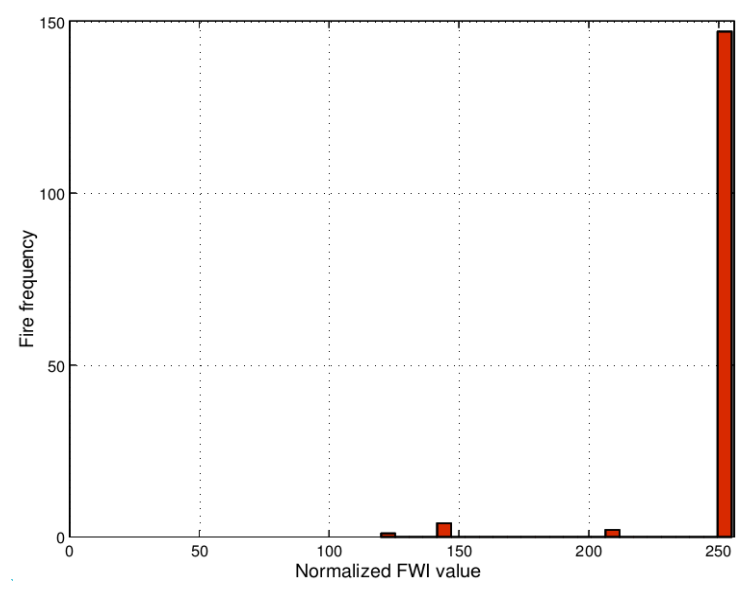

Figure 2. Relation between normalized FWI index RFw and fire frequency during year 2012.

Figure 2 shows the relation between FWI index and 154 historical wildfires that occurred during the year 2012. As we can see from the figure, most of the wildfires occurred under a very high FWI index; however, this is due to the low spatial resolution of FWI index where most of the terrain during the summer season is labelled as a high-risk territory. Although we believe that there exists territory with lower level of wildfire risk, we decided to take FWI index as a parameter in the calculation of the proposed site-specific wildfire risk index. Let us denote parameter based on Canadian fire feather index as RFWI.

Our study has shown that the slope of the terrain in combination with wind speed (Rst) as well as the aspect of the terrain in combination with wind direction (Rat) have greater influence on wildfire risk than wind speed and wind direction alone. We use the following equations to calculate those two subindexes:

$$
R_{\text {st }}=\left(\text { wind }_{\text {speed }}+\text { slope }\right)_{\text {norm_ } 0-255}, R_{a t}=\left(\left|\cos \left(\frac{\text { wind }_{\text {dir }}-\text { aspect }}{2}\right)\right|\right)_{\text {norm_ } 0-255}
$$
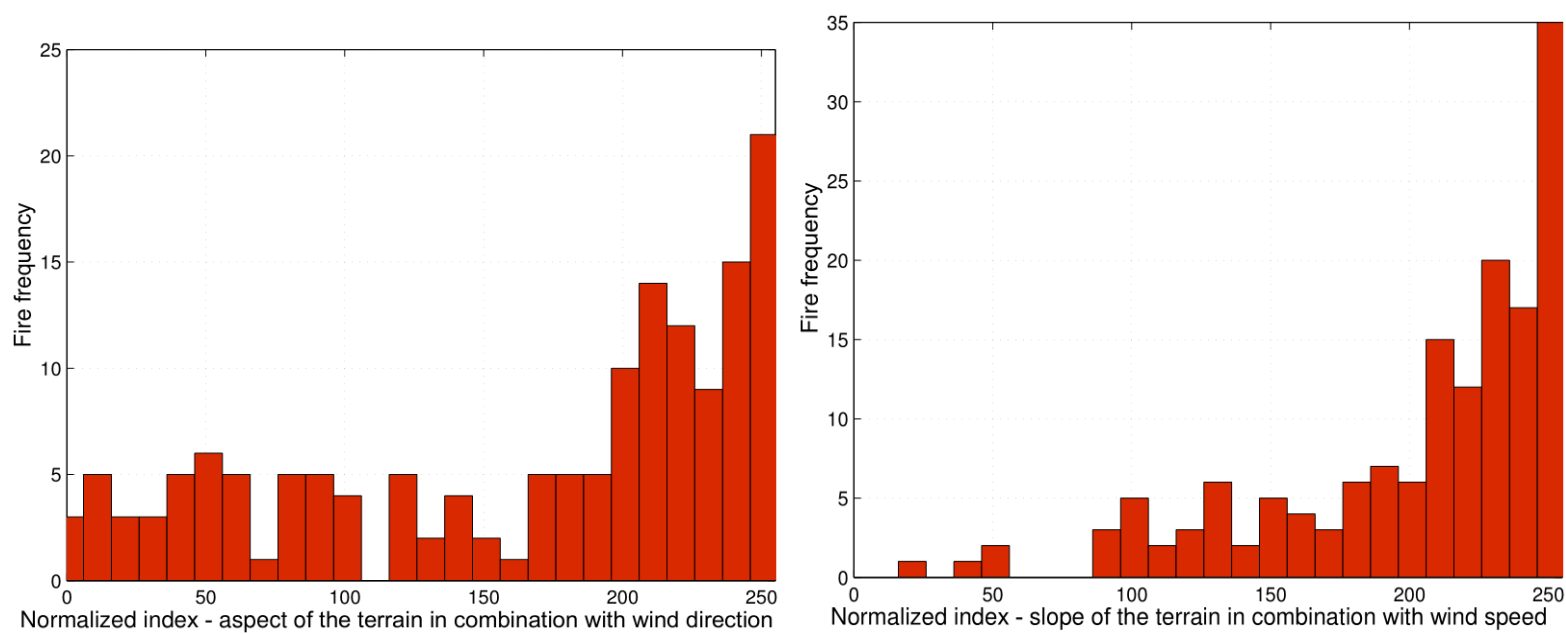

Figure 3. Relation between normalized indexes based on terrain and wind conditions $\left(\boldsymbol{R}_{a t}, \boldsymbol{R}_{\text {st }}\right)$ and fire frequency during year 2012.

The graphs showing the normalized indexes are presented in Figure 3. Again, 154 historical wildfires that occurred during the year 2012 were taken into account. 


\subsection{Vegetation parameters}

Fire spreads after ignition by igniting surrounding fuel in presence of oxygen. Amount of fuel depends on type of vegetation and soil. As already mentioned, FBPS fuel model was not developed for the Adriatic region, therefore in this paper we propose a conversion table used to convert from CLC classes to FBPS fuel model (Table 1).

Categories from FBPS fuel model were also normalized into interval [0 255]. Relation between the fuel model sub-index (Rfm) and 1146 historical wildfires that occurred in Split-Dalmatia County from January 1st 2001 to January 1st 2013 is given in Figure 4 (left).

Table 2. Conversion of CLC (Corine Land Cover) classes to FBPS fuel classes

\begin{tabular}{ccccccccccccccc}
\hline CLC & 111 & 112 & 121 & 122 & 123 & 124 & 131 & 132 & 133 & 141 & 142 & 211 & 212 & 213 \\
\hline FBPS & 0 & 0 & 0 & 0 & 0 & 0 & 0 & 0 & 0 & 0 & 0 & 11 & 0 & 0 \\
CLC & 221 & 222 & 223 & 231 & 241 & 242 & 243 & 311 & 312 & 313 & 321 & 322 & 323 & 324 \\
FBPS & 2 & 10 & 7 & 1 & 12 & 12 & 12 & 9 & 8 & 8 & 1 & 0 & 5 & 2 \\
CLC & 331 & 332 & 333 & 334 & 411 & 421 & 422 & 423 & 511 & 512 & 521 & 523 & & \\
FBPS & 0 & 0 & 0 & 0 & 0 & 0 & 0 & 0 & 0 & 0 & 0 & 0 & \\
\hline
\end{tabular}
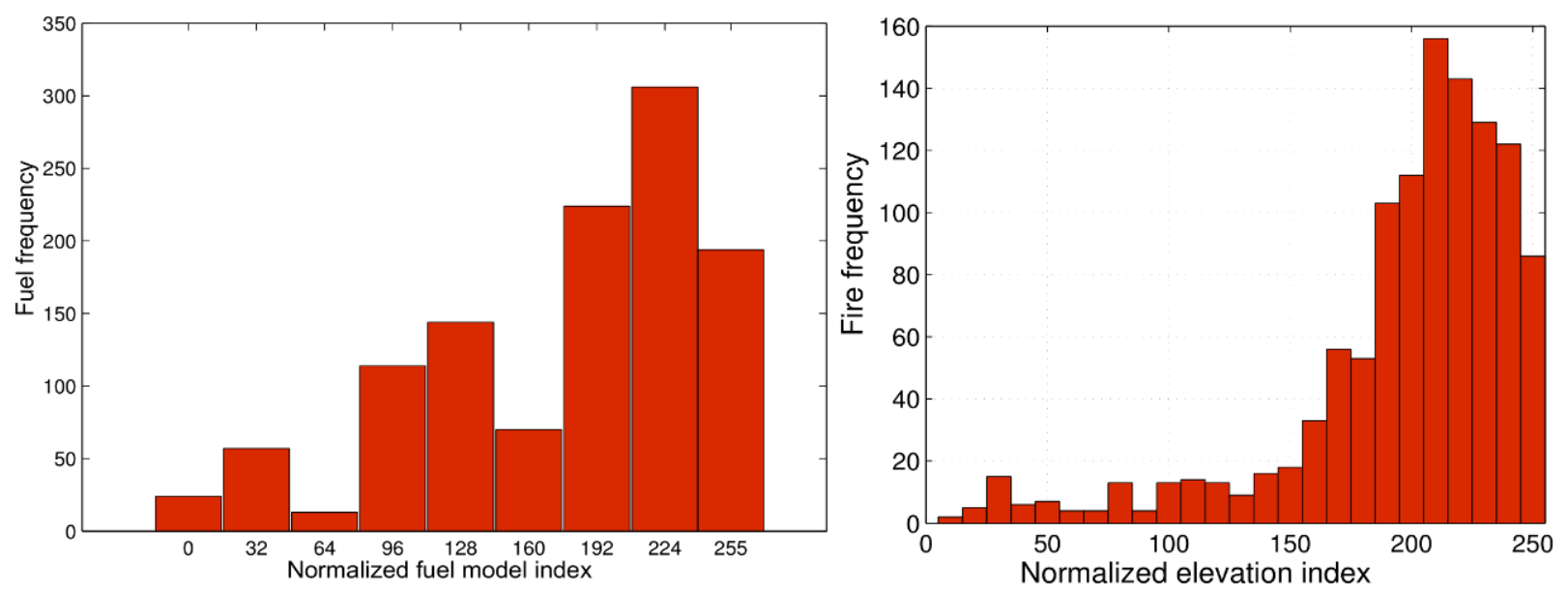

Figure 4. Relation between normalized fuel model index $\mathrm{R}_{\mathrm{fm}}$ and historical wildfires (left) and relation between normalized elevation index $\mathrm{R}_{\mathrm{el}}$ and historical wildfires (right)

\subsection{Terrain configuration}

Terrain configuration has two effects, first it has an influence on wildfire risk, but also it has an inevitable impact on the way the fire spreads after the ignition. In the previous sections we have already shown how terrain configuration in combination with wind speed and wind direction affects the wildfire risk index. In this section we investigate the influence of the terrain elevation.

Higher altitude means lower temperatures, what has a direct impact on the risk of fire ignition. There is also an indirect impact on wildfire risk index through the type of vegetation growing at certain altitudes. Normalized elevation sub-index $\left(\mathrm{R}_{\mathrm{el}}\right)$ was created by normalizing altitudes from $0 \mathrm{~m}$ to $1000 \mathrm{~m}$ into interval [0 255] (whereas lower altitude represents higher index). The relation between normalized elevation index and 1146 historical fires is shown in Figure 4 (right).

\subsection{Anthropogenic parameters}

In most cases of wildfires, humans are often responsible for fire ignition. Human activity is highly correlated with wildfires, no matter if fires were caused deliberately, or started by human negligence or ignorance. Fires caused by arson are often in a close proximity to humans and human infrastructure. 
On the other hand, negligence, such as uncontrolled agricultural burning, can also be a significant cause of wildfires. These are just a few examples where the human is the main culprit for wildfire ignition.

A first group of anthropogenic parameters refers to the distance from the human activities. In our study we investigated: the distance from roads and the distance from settlements. In order to determine the influence of the roads, we first formed a corridor close to the roads because we suppose that close to the roads the wildfire risk is higher. The width of the corridor was set to $2000 \mathrm{~m}$, since in our study we observed that most of the historic wildfires occurred within this distance. Similarly, for the influence correlated with the distance from settlements, we formed a zone around the settlements of $15000 \mathrm{~m}$ (again, highest value of the normalized sub-index is in the close vicinity of the settlements). Graphs representing the relation of historical wildfires with normalized sub-indexes representing distance from roads $\left(\mathrm{R}_{\mathrm{ro}}\right)$ and buildings $\left(\mathrm{R}_{\mathrm{bu}}\right)$ are given in Figure 5.
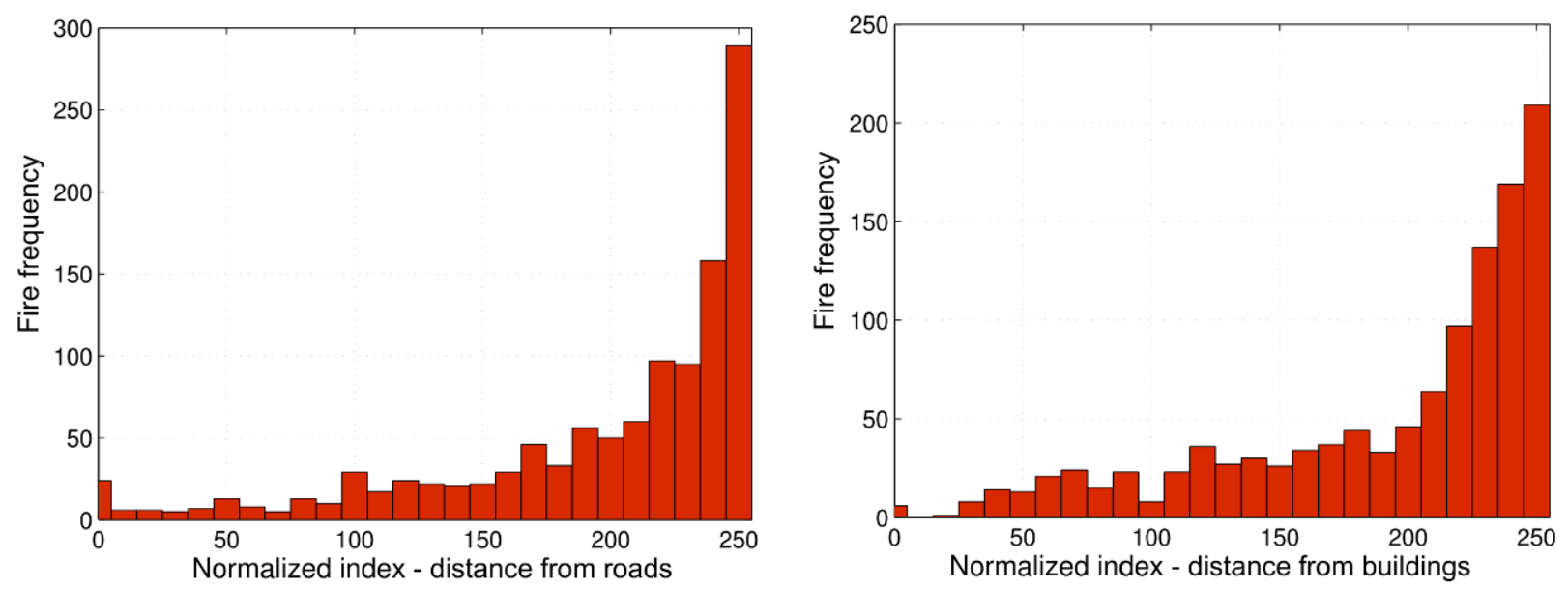

Figure 5. Relation between normalized index based on distance from roads $\mathbf{R}_{\mathbf{r o}}$ and historical wildfires (left), relation between normalized index based on distance from settlements $\mathbf{R}_{\mathrm{bu}}$ and historical wildfires (right)
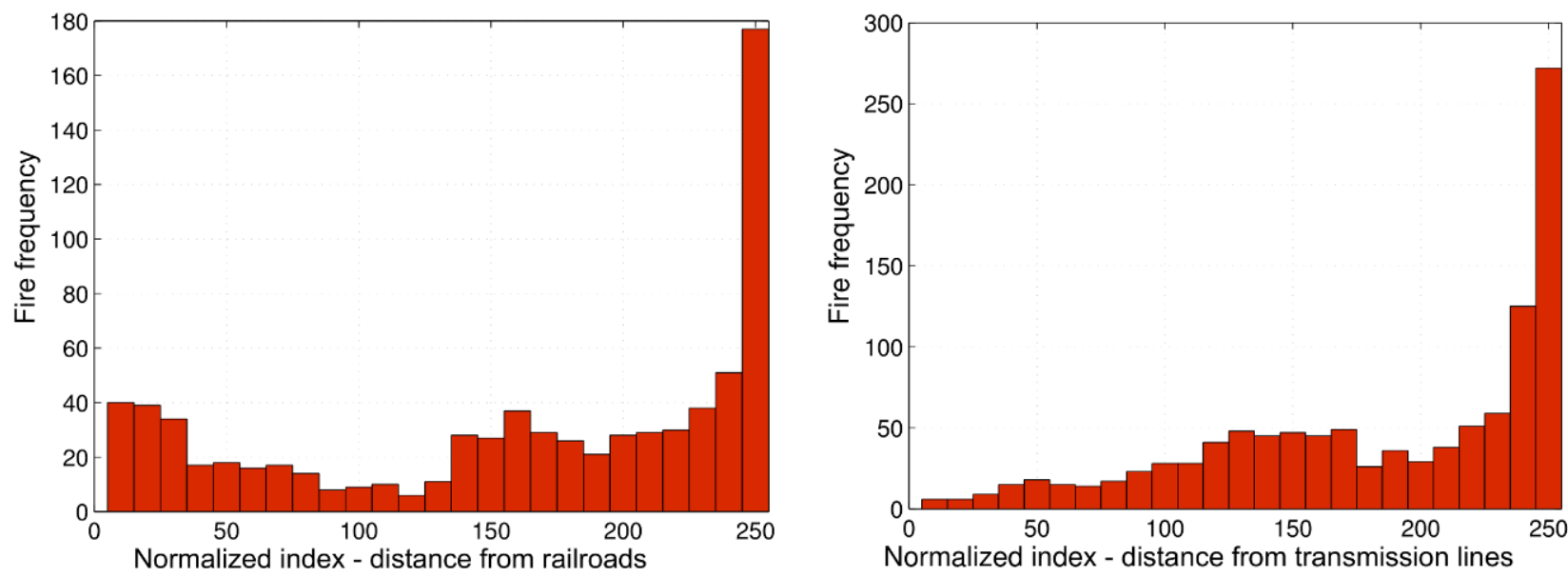

Figure 6. Relation between normalized index based on distance from railroads and historical wildfires (left), relation between normalized index based on distance from transmission lines $\mathbf{R}_{\mathrm{tl}}$ and historical wildfires (right)

The second group of anthropogenic parameters refers to the distance from human infrastructure, i.e., the distance from railroads and the distance from transmission lines. In the vicinity of the railroads wildfires often start from sparks caused by braking of the trains. However, our study has shown low correlation between historical wildfires and distance from railroads, therefore we decided to omit this sub-index from the final model (Fig 6 (left)). When we studied influence of transmission lines on 
wildfire risk index, we formed a corridor with width $2000 \mathrm{~m}$. Normalized index that takes into account the distance from transmission lines $\left(\mathrm{R}_{\mathrm{tl}}\right)$ is shown in Figure 6 (right).

For all the parameters we have calculated Pearson correlation coefficients, as shown in Table 2. Pearson correlation coefficient is a measure of the linear correlation (dependence) between two variables, in this case between a certain sub-index and fire frequency. Maximal correlation is 1.

Table 2. Pearson correlation coefficients for sub-indexes building used for SWRI index calculation

\begin{tabular}{llc}
\hline Sub-index & $\begin{array}{c}\text { Pearson correlation } \\
\text { coefficient }\end{array}$ \\
\hline $\mathbf{R}_{\mathbf{e l}}$ & Elevation index & 0.8404 \\
$\mathbf{R}_{\mathbf{f m}}$ & Fuel model index & 0.8340 \\
$\mathbf{R}_{\mathbf{b u}}$ & Index based on distance from buildings & 0.7814 \\
$\mathbf{R}_{\mathbf{s t}}$ & Index based on slope of the terrain and wind speed & 0.7740 \\
$\mathbf{R}_{\mathbf{r o}}$ & Index based on distance from roads & 0.7044 \\
$\mathbf{R}_{\mathbf{a t}}$ & Index based on aspect of terrain and wind direction & 0.6470 \\
$\mathbf{R}_{\mathbf{t l}}$ & Index based on distance from transmission lines & 0.6408 \\
\hline
\end{tabular}

\section{Site-specific wildfire risk index (SWRI) model definition}

Site-specific wildfire risk index (SWRI) takes the following sub-indexes as inputs: Canadian fire weather index $\left(\mathrm{R}_{\mathrm{FWI}}\right)$, elevation index $\left(\mathrm{R}_{\mathrm{el}}\right)$, fuel model index $\left(\mathrm{R}_{\mathrm{fm}}\right)$, index based on the distance from buildings $\left(\mathrm{R}_{\mathrm{bu}}\right)$, index based on the slope of terrain and wind speed $\left(\mathrm{R}_{\mathrm{st}}\right)$, index based on the distance from roads $\left(R_{\mathrm{ro}}\right)$, index based on the aspect of the terrain and wind direction $\left(\mathrm{R}_{\mathrm{at}}\right)$ and index based on the distance from transmission lines $\left(\mathrm{R}_{\mathrm{tl}}\right)$. An overview of all sub-indexes and their dependencies is given in Figure 7.

In order to calculate SWRI index we have used in this phase a simple linear model of superposition of input parameters, as shown in the following linear equation:

$$
S W R I=k_{1} \cdot R_{F W I}+k_{2} \cdot R_{e l}+k_{3} \cdot R_{f m}+k_{4} \cdot R_{b u}+k_{5} \cdot R_{s t}+k_{6} \cdot R_{r o}+k_{7} \cdot R_{a t}+k_{8} \cdot R_{t l}
$$

where $\sum_{n=1}^{8} k_{n}=1$. In order to determine the values $k_{n}$ we have decided to use genetic algorithms (Goldberg, 1989). Genetic algorithm is a search heuristic that mimics the process of natural selection. It is used to generate solution to optimization problems using techniques inspired by natural evolution, such as inheritance, mutation, selection and crossover. The most difficult task in genetic algorithm designing is to define a fitness function for measuring the quality of the represented solution.

Our approach was to defined two sets of geographic locations for which we wanted to calculate a sitespecific wildfire risk index. The first set consisted of locations of real historical wildfires that occurred during year 2012 in Split-Dalmatia County (we have randomly chosen 100 historical wildfires from that period). The second set consisted of randomly chosen locations in Split-Dalmatia County (we have selected 250 locations).

The following requirements for the data set representing the SWRI index calculated for locations of real historical wildfires were defined: a) the data set should be as close as possible to maximal value 255, b) the data set should be normally distributed - for normality test we used the Spiegelhalter test (Spiegelhalter, 1983), and c) the data set should be maximally skewed to the left, measured using Fisher-Pearson standardized moment coefficient (Doane \& Seward, 2011). 


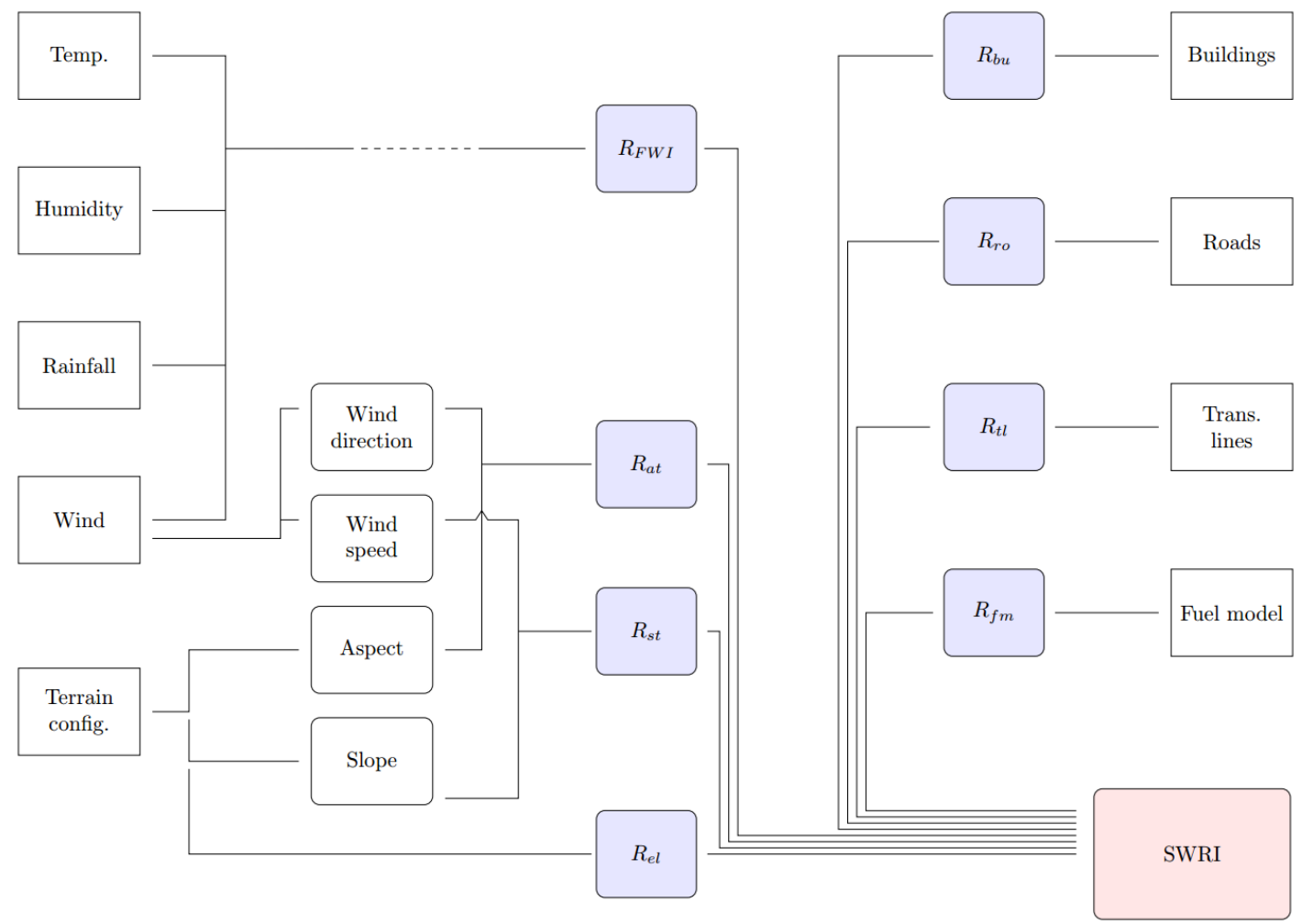

Figure 7. Overview of all inputs and sub-indexes that build up the final site-specific wildfire risk index

The requirements for the data set representing the SWRI index calculated for randomly chosen locations were defined as follows: a) the data set should be normally distributed (also measured using Spiegelhalter test for normality), b) the standard deviation of the data set should be as high as possible. Using the aforementioned requirements we represented the wildfire risk index model definition as an optimization problem. We included Pearson correlation coefficients into the fitness function for the genetic algorithm in a way it defines the mutual ratio of coefficients ${ }^{k_{n}}$ with the following restriction $\sum_{n=1}^{8} k_{n}=1$. The value of the fitness function $z$ was defined by:

$$
z=-0.5 \cdot\left|G_{\text {real }} \cdot \overline{\text { Mode }_{\text {real }}} \cdot p_{\text {real }}\right|-0.5 \cdot\left|\overline{\sigma_{\text {random }}} \cdot p_{\text {random }}\right|
$$

where subscript $(\cdot)_{\text {real }}$ represents real historical wildfires, and $(\cdot)_{\text {random }}$ represents randomly chosen locations. Parameter $G$ represents Fisher-Pearson standardized moment coefficient where negative values represent skewness to the left, $\overline{M o d e}$ is the mode of the dataset normalized into interval [0 1], $p$ the value of Siegelhalter test for normality where value 1 represents normal distribution, and $\bar{\sigma}$ represents a standard deviation normalized into interval [0 1 1]. Siegelhalter test for normality $p$ is calculated using a set of equations shown in (3):

$$
p=1-\left|\frac{2}{\sqrt{\pi}} \int_{0}^{\frac{s}{\sqrt{2}}} e^{-t^{2}} d t\right| \quad s=\frac{R-0.73 \cdot I}{0.8969 \cdot \sqrt{I}}, \quad R=\sum_{i=1}^{I}\left[\left(b_{i}-\bar{b}\right) \cdot \rho\right]^{2} \cdot \ln \left\{\left[\left(b_{i}-\bar{b}\right) \cdot \rho\right]^{2}\right\} \quad \rho=\sqrt{\frac{1}{I} \sum_{i=1}^{I}\left(b_{i}-\bar{b}\right)^{2}}
$$

where $\bar{b}$ represents the arithmetic mean of the data set and $I$ represents the number of elements of the same data set. Fisher-Pearson standardized moment coefficient $G$ is defined by 


$$
G=\frac{I}{(I-1)(I-2)} \cdot \sum_{i=1}^{I}\left(\frac{b_{i}-\bar{b}}{\sigma}\right)^{3}
$$

Table 3. Results of the genetic algorithm

\begin{tabular}{|c|c|c|c|c|c|}
\hline \multicolumn{3}{|c|}{$\begin{array}{c}\text { Randomly chosen locations representing } \\
\text { historical wildfires } \\
\end{array}$} & \multicolumn{3}{|c|}{ Randomly chosen locations } \\
\hline$\overline{M o d e_{\text {real }}}$ & $\overline{p_{\text {real }}}$ & $\overline{G_{\text {real }}}$ & $\sigma_{\text {random }}$ & $p_{\text {random }}$ & $\mathrm{Z}$ \\
\hline 0.8824 & 0.9216 & -0.6951 & 0.1522 & 0.0788 & -0.2886 \\
\hline
\end{tabular}

Please note that the more negative values of the fitness function $z$, the better the results. The output of the genetic algorithm (Table 3) provided us with the final linear equation that defines the site-specific wildfire risk calculation:

$$
S W R I=0.399 \cdot R_{F W I}+0.097 \cdot R_{e l}+0.096 \cdot R_{f m}+0.09 \cdot R_{b u}+0.089 \cdot R_{s t}+0.081 \cdot R_{r o}+0.075 \cdot R_{a t}+0.073 \cdot R_{t l} \quad(5
$$

Equation was implemented into Grass GIS software to calculate SWRI index several times a day. The output of the calculation is a SWRI index in a raster format. Using Mapserver we create a WMS layer that can easily be shown using Openlayers in a web based user interface. As shown in Figure 8, our system automatically communicates with Croatian Meteorological and Hydrological Service (DHMZ) several times a day in order to retrieve the latest data such as current temperature, wind speed, wind direction, rainfall, humidity, as well as the Canadian Forest Fire Weather Index (FWI).

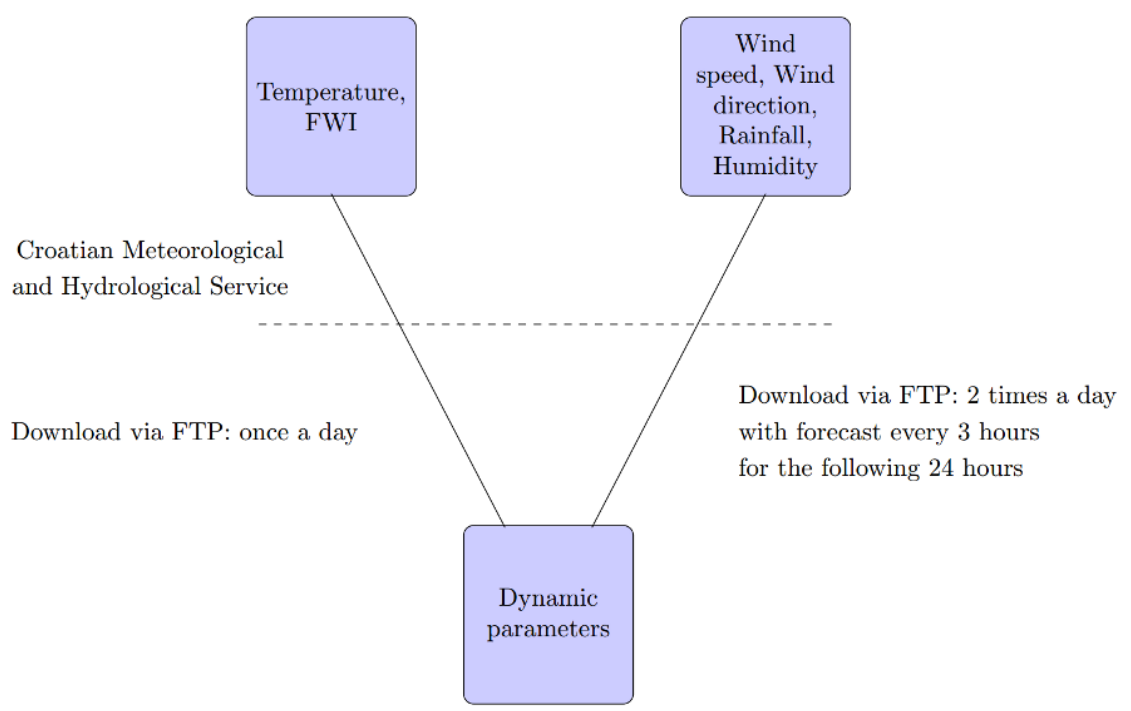

Figure 8. Communicating with Croatian Meteorological and Hydrological Service

\section{SWRI model evaluation}

The level of forest fire risk in Croatia is determined by the "Static forest fire risk" defined in the "Criteria for assessing the risk of forest fires" ((MUP, 2003), therefore we decided to compare it to 
the proposed SWRI index. Parameters taken into account in "Static forest fire risk" are as follows: vegetation cover, anthropogenic parameters, climate, habitat, insolation and forest order. For this index, regions are classified into 4 categories depending on the level of risk: i.e., category IV: low risk, category II: moderate risk, category II: high risk and category I: very high risk. Figure 9 (left) shows the region of Split-Dalmatia County classified into 4 aforementioned categories, while Figure 9 (right) shows the relation between 154 historical wildfires (that happened during year 2012. in the Adriatic region of Croatia) and the "Static forest fire indexes". As seen in this figure, most of the wildfires occurred in low risk regions, meaning that the "Static forest fire risk" does not predict wildfire risk index with high accuracy.
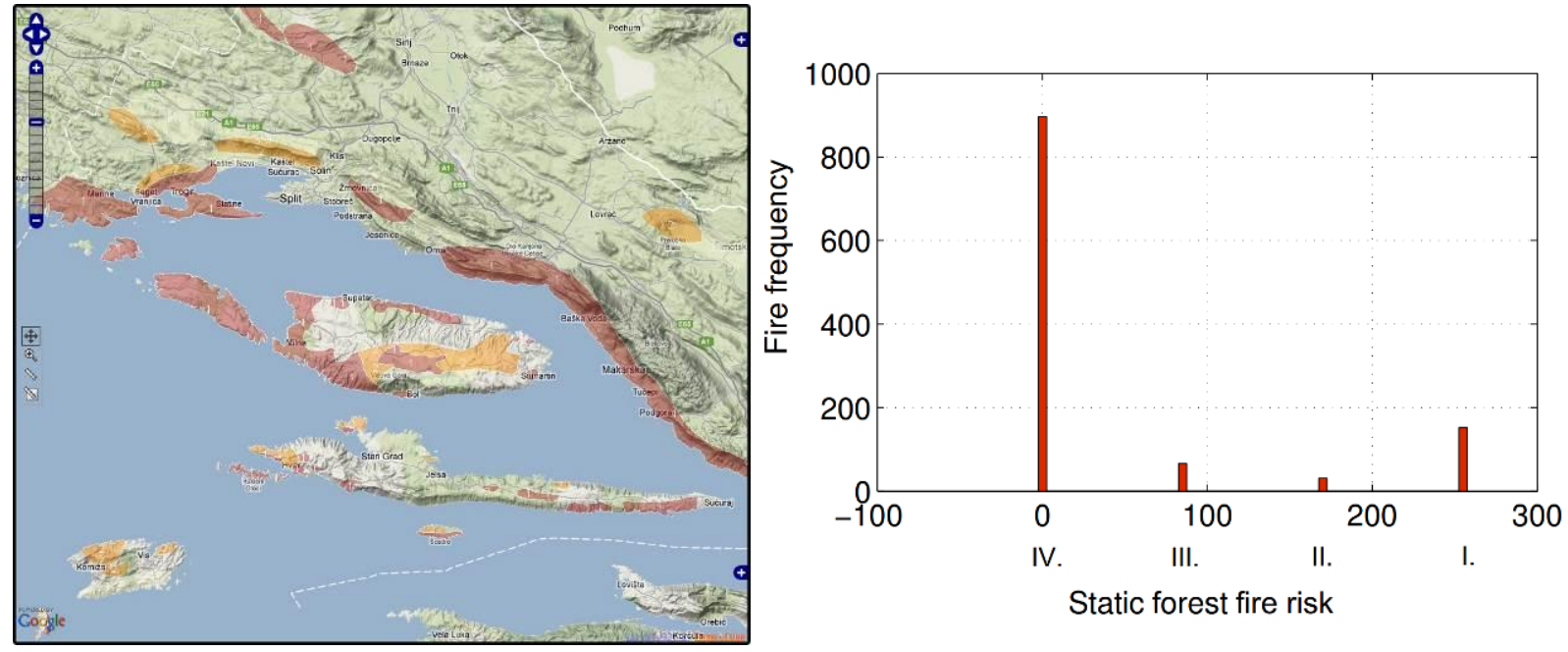

Figure 9. The region of Split-Dalmatia County classified into 4 static risk categories, where dark red colour represents the highest risk (left), and relation between historical wildfires that occurred during year 2012 "with Static forest fire indexes" (right).
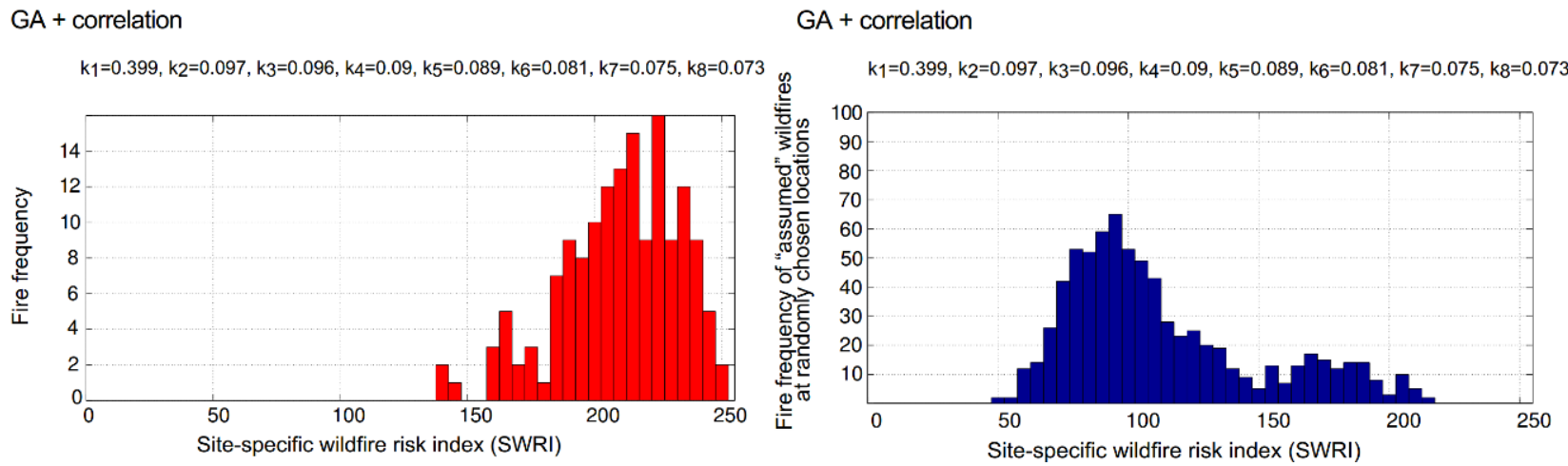

Figure 10. SWRI index for the 154 actual wildfires that occurred during year 2012 (left), and SWRI index for a randomly chosen locations and time moments during the same year

On the other hand, Figure 10 (left) shows the proposed SWRI index for the same 154 historical wildfires that occurred during the year 2012. From this figure it is obvious that most of the wildfires occurred in high risk regions. Nevertheless, in Figure 10 (right) we can see that, for 750 randomly chosen locations and time moments during the same year, the value of SWRI in most cases does not exceed 150, meaning that most of the regions are labelled as low or moderate risky regions. This is expected, as we have modelled SWRI index to be a site-specific index with a focus on a micro-location. 


\section{Conclusions}

In this paper we proposed a novel method for wildfire risk index calculation - the Site-specific Wildfire Risk Index (SWRI). The overall SWRI index is calculated based on 8 sub-indexes: Canadian fire weather index, elevation index, fuel model index, index based on the distance from settlements, index based on the slope of terrain and wind speed, index based on the distance from roads, index based on the aspect of the terrain and wind direction and index based on the distance from transmission lines. All sub-indexes were chosen based on the statistical evaluation, where we have, for all sub-indexes, calculated Pearson correlation coefficients that show their relation to the historical wildfires in the Adriatic region. In other words, for all sub-indexes we have proven their influence on the actual wildfires that occurred in Split-Dalmatia County in the history.

Using genetic algorithms and calculated Pearson correlation coefficients, we have created a final model of SWRI index. We carried out the evaluation of the proposed site-specific wildfire risk index and compared it to the "Static forest fire index", where we have shown that SWRI index provides good correspondence with the actual wildfires that occurred in the Adriatic region in recent years. On the other hand, for randomly chosen locations, the value of SWRI index in most cases indicated a low or a moderate level of risk. This was expected, since SWRI index was modelled with focus on a microlocation and the fact that even in the fire season not all regions should be labelled as regions of high risk.

SWRI index is calculated using geographical information system (GIS), and its main purpose is to display relevant information important for firefighting activities before and during the actual wildfire. The SWRI index should also be optimized for other parts of Adriatic regions besides Split-Dalmatia County using the same methodology for more general results.

\section{References}

(Anderson, 1982) Anderson, H. E. 1982. Aids to determining fuel models for estimating fire behavior. Tech. rept. U.S.D.A. Forest Service, Intermountain Forest and Range Experiment Station, Ogden, Utah.

(Bugaric et al., 2009) Bugarić, M., Jakovčević, T., \& Stipaničev, D. 2009 (May). Automatic adjustment of detection parameters in forest fire video monitoring system. Pages 270-275 of: Proc. of 32. Int. Conference MIPRO.

(Burgan, 1998) Burgan, R. E., Klaver, R. W., \& Klaver, J. M. 1998. Fuel models and fire potential from satellite and surface observations. International Journal of Wildland Fire, 8(3), 159-170.

(Doane \& Seward, 2011) Doane, David P., \& Seward, Lori E. 2011. Measuring Skewness: A Forgotten Statistic: Journal of Statistics Education, 19(2), n2.

(Erten, 2002) Erten, E., Kurgun, V., \& Musaoglu, N. 2002. Forest Fire Risk Zone Mapping From Satellite Imagery And GIS: A Case Study. International Journal of Applied Earth Observation and Geoinformation, 4, 1-10.

(FWI, 2009) "Canadian Forest Fire Weather Index (FWI) System". Background Information. Natural Resources Canada. 2009. Retrieved 2009-09-13.

(Goldberg, 1989) Goldberg, David E. 1989. Genetic algorithms in search, optimization, and machine learning. Addison-Wesley Professional.

(Gould, 2003) Gould, Michael, Laurini, Robert, \& Coulondre, Stéphane. 2003. AGILE 2003: 6th AGILE Conference on Geographic Information Science. PPUR presses polytechniques.

(Hernandez-Leal, 2008) Hernandez-Leal, P.A., Gonzalez-Calvo, A., Arbelo, M., Barreto, A., \& Alonso-Benito, A. 2008. Synergy of GIS and Remote Sensing Data in Forest Fire Danger Modeling. IEEE Journal of Selected Topics in Applied Earth Observations and Remote Sensing, 1(4), 240 247. 
(Mapserver, 2014) http://mapserver.org/, Welcome to MapServer - MapServer 6.4.1 documentation, 06. June 2014.

(MUP, 2003) 2003. Ministarstvo unutarnjih poslova, Pravilnik o zaštiti šuma od požara.

(NASA, 2014)http://earthdata.nasa.gov/data/near-real-time-data/data/firms/active-fire-data, Active Fire Data | EOSDIS - Earth Data Website, 06. June 2014.

(NDVI, 2014) http://earthobservatory.nasa.gov/Features/MeasuringVegetation/

(Neteler \& Mitasova, 2008) Neteler, Markus, \& Mitasova, Helena. 2008. Open Source GIS: A GRASS GIS Approach. The International Series in Engineering and Computer Science. Springer New York Inc.

(Netolicki, 2012) Netolicki, Antonija, Blaževic, Tomislav, \& Antolovic, Andrija. 2012. Multicriteria Analysis of Fire Risk in the Split-Dalmatia County. Kartografija i geoinformacije, 11(17), 4, 5-24, 24.

(NFDRS, 1988) Burgan, Robert E. 1988. 1988 revisions to the 1978 National Fire-Danger Rating System. Res. Pap. SE-273. Asheville, NC: U.S. Department of Agriculture, Forest Service, Southeaster Forest Experiment Station. 39 pp

(Openlayers, 2014) http://openlayers.org/, Openlayers: Home, , 06. June 2014.

(OpenStreetMap, 2014) http://www.openstreetmap.org/, OpenStreetMap, 06. June 2014.

(Pearson, 1805) Karl Pearson,1895, Notes on regression and inheritance in the case of two parents, Proceedings of the Royal Society of London, $58: 240-242$.

(Preisler, 2004) Preisler, H. K, Brillinger, D. R, Burgan, R. E, \& Benoit, J. W. 2004. Probability based models for estimation of wildfire risk. International Journal of Wildland Fire, 13(2), 133-142.

(San-Miguel-Ayanz, 2002) San-Miguel-Ayanz, J. 2002. Towards a coherent forest fire information system in Europe: the European Forest Fire Information System (EFFIS). Forest fire research \& wildland fire safety, 46, 5-16.

(Scott \& Burgan, 2005) Scott, J. H., \& Burgan, R. E. 2005. Standard fire behavior fuel models: a comprehensive set for use with Rothermel's surface fire spread model. Tech. rept. USDA Forest Service, Rocky Mountain Research Station.

(Setiawan, 2004) Setiawan, I., Mahmud, A. R, Mansor, S., Shariff, A. R.M, \& Nuruddin, A. A. 2004. GIS-grid-based and multi-criteria analysis for identifying and mapping peat swamp forest fire hazard in Pahang, Malaysia. Disaster Prevention and Management, 13(5), 379-386.

(Silveira, 2008) Silveira, H. L.F, Vettorazzi, C. A, \& Valente, R. O.A. 2008. Multi-criteria evaluation of a GIS environment in a forest fire hazard mapping for the Corumbata River basin, SP, Brazil. Revista Árvore, 32(2), 259-268.

(Spiegelhalter, 1983) Spiegelhalter, D. J. 1983. Diagnostic tests of distributional shape. Biometrika, 70(2), 401-409.

(van Zyl, 2001) van Zyl, J. J. 2001. The Shuttle Radar Topography Mission (SRTM): a breakthrough in remote sensing of topography. Acta Astronautica, 48(5), 559-565.

(Vasilakos, 2007) Vasilakos, C., Kalabokidis, K., Hatzopoulos, J., Kallos, G., \& Matsinos, Y. 2007. Integrating new methods and tools in fire danger rating. International Journal of Wildland Fire, 16(3), 306-316.

(Yang \& Di, 2011) Yang, Guang, \& Di, Xueying. 2011 (June). Adaptation of Canadian Forest Fire Weather Index system and it's application. Pages 55-58 of: IEEE International Conference on Computer Science and Automation Engineering (CSAE), vol. 2.

(Zhijun, 2009)Zhijun, T., Jiquan, Z., \& Xingpeng, L. 2009. GIS-based risk assessment of grassland fire disaster in western Jilin province, China. Stochastic Environmental Research and Risk Assessment, 23(4), 463-471. 